\title{
TITLE:
}

\section{Greetings to all Pan Africanists from Kyoto!}

$\operatorname{AUTHOR}(\mathrm{S})$ :

Nishida, Toshisada

\section{CITATION:}

Nishida, Toshisada. Greetings to all Pan Africanists from Kyoto!. Pan Africa News 1994, 1(1): 1-1

ISSUE DATE:

1994

URL:

http://hdl.handle.net/2433/143541

RIGHT:

Copyright (C) Pan Africa News. 


\section{Greetings to all Pan Africanists from Kyoto!}

We are happy to present to you the first issue of Pan Africa News, the official newsletter of both the Japan Committee for the Conservation and Care of Chimpanzees, and the Mahale Wildlife Conservation Society. The title was suggested by Jane Goodall, who has in the past encouraged us to produce such a newsletter. "Pan", of course, represents the genus Pan which is our subject of study; it also represents our goal, which is to share information on all aspects of chimpanzee fieldwork conducted all across Africa. We hope to facilitate communication of a friendly, informal nature among field workers who wish not only to study chimpanzees, but also to conserve them in their dwindling habitat.

The study of great apes in the wild has been hampered by political instability. Regional wars and skirmishes, most recently in Rwanda, Cameroon and Liberia, have brought misery to thousands of humans, and also threatened the existence of great apes across a wide area of Africa. Although a peace treaty was signed in Rwanda last summer and researchers have returned to Karisoke, most field studies in Zaire and the Congo are still at a halt. The camp at Wamba in Zaire, for example, where bonobos have been studied, has been closed now for over two years, and the camp at Ndoki in the Congo has been inaccessible to researchers for more than one year. Field workers responsible for those sites, however, are ready to reinitiate their studies whenever the political situation improves.

Due to constant change, many people, even active scientists working at the forefront of a field, can be uninformed about ongoing studies and the conservation status of chimpanzees at sites other than their own. New studies begin such as the ones at Kalinzu Forest in Uganda and Mt. Nimba in Cote d'Ivoire, interest is rekindled in older sites such as Budongo Forest in Uganda, and grows in areas such as the Ugalla Hills of Tanzania, to where Takayoshi Kano and his colleagues are now planning a trip. We hope to bring you information about all of these places, in addition to news from well-known, long-term sites.

My wish is that this newsletter be a forum through which field workers can freely exchange information, opinion, advice and comment on chimpanzee research and conservation in Africa. We plan to print the newsletter twice yearly, but could make it quarterly if we find there is sufficient interest.

I thank Linda Turner who has agreed to edit this first issue, and also WWF Japan which provided funds for its publication. Finally, I thank everyone for all they have done and are doing for chimpanzees across Africa, and wish you best of luck.

Toshisada Nishida, Kyoto University 